\title{
BRAIN VOLUMES OF THE LAMB, RAT AND BIRD DO NOT SHOW HEMISPHERIC ASYMMETRY: A STEREOLOGICAL STUDY
}

\author{
BÜNYAMIN SAHIN ${ }^{1}$, HÜSEYIN ASLAN ${ }^{2}$, BÜNYAMI UNAL ${ }^{3}$, SINAN CANAN $^{4}$, SAIT BILGIC ${ }^{1}$, \\ SÜLEYMAN KAPLAN ${ }^{2}$ AND LEVENT TUMKAYA ${ }^{2}$
}

${ }^{1}$ Ondokuz May1s University, Medical School, Department of Anatomy, 55139, Samsun, TURKEY, ${ }^{2}$ Ondokuz Mayis University, Medical School, Department of Histology and Embryology, 55139, Samsun, TURKEY, ${ }^{3}$ Gaziantep University, Medical School, Department of Histology and Embryology, 27310, Gaziantep, TURKEY, ${ }^{4}$ Ondokuz Mayis University, Medical School, Department of Physiology 55139, Samsun, TURKEY e-mail: bsahin@omu.edu.tr, bunyamiunal@hotmail.com, sinancanan@superonline.com (Accepted March 2, 2001)

\begin{abstract}
It is well known that there are functional differences between right and left brain hemispheres. However, it is not clear whether these functional differences are reflected in morphometric differences. This study was carried out to investigate the right-left asymmetry, and sex and species differences of the brains using the Cavalieri principle for volume estimation. Seventeen lambs, 10 rats and 12 avian brains were used to estimate brain volumes. A transparent point grid was superimposed on the slices of lamb brains directly and the slices of the rat and avian brains were projected onto a screen at 10x magnification. Surface areas of the cut slice faces were estimated by simply counting the points that hit the slices. Mean brain volumes were $37.74 \mathrm{~cm}^{3}, 598.95 \mathrm{~mm}^{3}$ and $730.38 \mathrm{~mm}^{3}$ and the coefficients of variations were $0.08,0.05$ and 0.05 for lamb, rat and avian brains respectively. The differences between left and right hemispheres did not show statistical significance $(\mathrm{P}>0.05)$. However, the male brain volumes were larger than the females for the lamb and bird $(\mathrm{P}<0.05)$. In light of such findings, it will be necessary to evaluate neuron number of the brain hemispheres to provide more useful data regarding inter-hemispheric brain asymmetry.
\end{abstract}

Keywords: asymmetry, bird, brain volume, Cavalieri principle, lamb, rat.

\section{INTRODUCTION}

It is well known that lateralization of function and structure is a feature of the human brain as well as that of other species, including birds and other vertebrates (Kolb et al., 1982; Williams et al., 1989; Mayhew et al., 1996a; 1996b). However, it is not clear if these functional differences are reflected in morphologic or morphometric differences. Moreover, sex differences of brain volume are also not clearly established. Most of the previous studies on brain asymmetry are based on evaluating imprecisely defined features of the brain, i.e. height, width and length of hemisphere or shape of the gyri. In contrast, estimating brain volume using Cavalieri principle is a more valid method (Gundersen et al., 1988).

Many studies have been done on the symmetry or asymmetry of brain volume as a basis for an interaction between the function and morphology.
However, findings of such studies are incompatible with one another for methodological or other reasons (Schultz et al., 1994; Barta et al., 1997; Frangou et al., 1997; Preis et al., 1999; Geroldi et al., 2000).

The present study was carried out to investigate the right-left interhemispheric asymmetry, sex and species differences using the Cavalieri principle.

\section{MATERIALS AND METHODS:}

In this study 17 lambs (10 male, 7 female, Ovis aries), 10 rats (5 male, 5 female, Wistar albino) and 12 birds ( 7 cocks, and 5 hens, Gallus domesticus) were used. The lambs were 4-5 months old, while rats and birds were 8 weeks old. The rats were perfused intracardially and the brains were immersed in formalin and fixed for four months. The lamb' and avian' brains were removed without perfusion and immersed in formalin (10\%) for four months. 

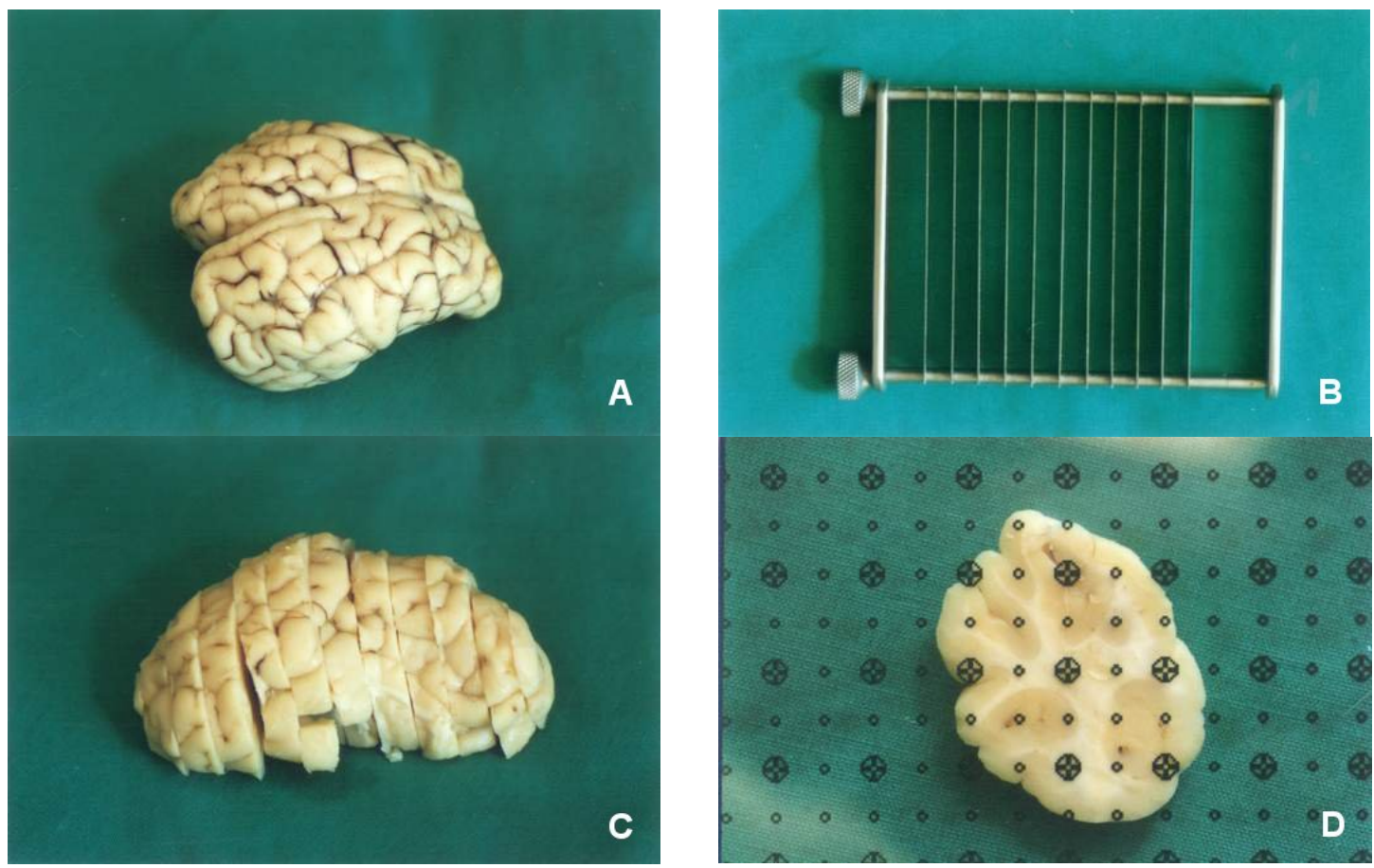

Fig. 1. Estimation of the lamb brain volume. 1A) The lamb brain, 1B) Fractionating knives, 1C) Brain slices cut in parallel, 1D) Estimation of the area of the slice using a transparent point grid.

Table 1. An example of the estimate of CE from 6 slices.

\begin{tabular}{llllllll}
\hline Section & 1st time & 2nd time & 3rd time & Mean & Pi.Pi & Pi.Pi+1 & Pi.Pi+2 \\
\hline 1 & 12 & 15 & 16 & 14,33 & 205,44 & 253,22 & 339,22 \\
2 & 19 & 16 & 18 & 17,66 & 312,11 & 418,11 & 453,44 \\
3 & 26 & 21 & 24 & 23,66 & 560,11 & 607,44 & 504,88 \\
4 & 28 & 24 & 25 & 25,66 & 658,77 & 547,55 & 128,33 \\
5 & 23 & 21 & 20 & 21,33 & 455,11 & 106,66 & 0 \\
6 & 6 & 4 & 5 & 5 & 25 & 0 & 0 \\
& & & & 107,66 & 2216,56 & 1933 & 1425,89 \\
& & & & & A & B & C \\
\hline
\end{tabular}

$$
\begin{gathered}
\text { Nug }=0.0724 \cdot(b / \sqrt{a}) \cdot \sqrt{n \cdot \sum P}=14.72 \\
\operatorname{Var}_{S R S}\left(\sum A\right)=(3(A-N u g)-4 B+C) / 12=24.94 \\
C E\left(\sum P\right)=\frac{\sqrt{\text { Total Var }}}{\sum P}=0.058 \\
C V=\text { Standard Deviation/Mean }
\end{gathered}
$$

(Gundersen and Jensen, 1987; West, 1993).

The brains were handled (Fig. 1A) and cut macroscopically with fractionating knives (Aygün Surgical Instruments in Turkey) into parallel sections (Fig. 1B). Slice thickness was $6.7 \mathrm{~mm}$ for the lamb (Fig. 1C), and $2.33 \mathrm{~mm}$ for the rat and the avian brains. From nine to eleven slices per lamb brain, five to six slices for rat and avian brains were used to estimate volumes. A modified point-counting grid which allowed checking of the boundaries of the white and gray mater was superimposed on the slices of the lamb brains directly (Fig. 1D). The slices of the rat and avian brains were projected onto a screen with a projector (Braun Paxiscope 650) at 10× magnification. 
Boundaries of the projections were drawn on paper, and the areas were estimated using the point counting probes. Brain volumes were estimated by the following formula:

$$
[V]=t \times a(p) \times \Sigma p
$$

$[V]=$ volume; $t=$ section thickness; $a(p)=$ area associated with one test point; $\Sigma p=$ total number of points hitting the brain section (Gundersen et al., 1988).

Coefficient of error (CE) and coefficient of variation (CV) were estimated (Gundersen and Jensen 1987; West, 1993). The point density of the grids was designed to obtain an appropriate $\mathrm{CE}$ for each animal group. At least, 5-6 brain slices were sufficient to obtain an adequate $\mathrm{CE}$ as shown in Table 1. Statistical analysis was done by a computer using SPSS software. Student's t-test was applied to compare sex and side differences of the data.

\section{RESULTS}

Results are summarized in Tables 2 and 3. The mean brain volumes were $37.74 \mathrm{~cm}^{3}, 598.95 \mathrm{~mm}^{3}$ and $730.38 \mathrm{~mm}^{3}$ and the coefficients of error were $0.08,0.05$ and 0.05 for lamb, rat and avian brain volume estimates respectively.

The comparison of the right versus left volumes of hemispheres and the male versus female total brain volumes are shown in Tables 2 and 3. The differences between left and right hemispheres were not statistically significant in all three animal groups. However, the differences between the male and female brain volumes were statistically significant
$(\mathrm{P}<0.05)$ in the case of lambs and birds - the male brain volumes were larger than those of females.

The mean lamb brain volume was $37.74 \pm 0.78 \mathrm{~cm}^{3}$. The mean cortical volume was $28.78 \pm 0.55 \mathrm{~cm}^{3}$ and the mean white matter volume was $8.96 \pm 0.32 \mathrm{~cm}^{3}$ for lambs. The mean cortical volume estimations were $29.78 \pm 0.93 \mathrm{~cm}^{3}$ for male lambs and $28.08 \pm 0.64 \mathrm{~cm}^{3}$ for female lambs. The right and left cortical volumes did not show statistical significance. The mean white matter volume was $10.25 \pm 0.52 \mathrm{~cm}^{3}$ in male lambs and $8.05 \pm 0.27 \mathrm{~cm}^{3}$ in female lambs. The white matter volumes were significantly different between the sexes $(P=0.0009)$. The detailed results of the estimates of lamb brain volumes are summarized in Tables 2 and 3 .

The mean avian brain volume was $730.38 \pm 17.35 \mathrm{~mm}^{3}$. While the mean volume of the hen brain was $689.03 \pm 17.03 \mathrm{~mm}^{3}$, the cock brain volume was $759.91 \pm 24.62 \mathrm{~mm}^{3}$. The mean volumes of the avian right and left hemisphere were $718.51 \pm 20.67 \mathrm{~mm}^{3}$ and $742.25 \pm 28.36 \mathrm{~mm}^{3}$. The detailed results of the avian brain volume estimates are summarized in Table 2 and 3.

The mean rat brain volume was $598.95 \pm 10.59 \mathrm{~mm}^{3}$. The mean volume of the rat brain was $592.40 \pm 13.09 \mathrm{~mm}^{3}$ for the females and $605.50 \pm 17.12 \mathrm{~mm}^{3}$ for the males. The mean volumes of the rat right and left hemisphere were $592.92 \pm 17.41 \mathrm{~mm}^{3}$ and $604.98 \pm 12.76 \mathrm{~mm}^{3}$. The detailed results of the rat brain volume estimates are summarized in Tables 2 and 3.

Table 2. The mean brain volume, coefficient of error (CE) and coefficient of variation $(C V)$ in lambs, rats and birds. *, \#:statistically significant difference.

\begin{tabular}{lccccccc}
\hline \multirow{9}{*}{ Species } & \multicolumn{9}{c}{ BRAIN VOLUME } & & \\
\cline { 2 - 6 } & $\begin{array}{c}\text { Right } \\
\text { hemisphere }\end{array}$ & Left hemisphere & Female & Male & Mean & CE & CV \\
\hline $\begin{array}{l}\text { Lamb } \\
\left(\mathrm{cm}^{3}\right)\end{array}$ & $38.57 \pm 1.09$ & $36.91 \pm 1.13$ & $36.13 \pm 0.79^{*}$ & $40.03 \pm 1.3^{*}$ & $37.74 \pm 0.78$ & 0.088 & 0.121 \\
$\begin{array}{l}\text { Rat } \\
\left(\mathrm{mm}^{3}\right)\end{array}$ & $592.92 \pm 17.41$ & $604.98 \pm 12.76$ & $592.4 \pm 13.09$ & $605.5 \pm 17.12$ & $598.95 \pm 10.59$ & 0.054 & 0.079 \\
$\begin{array}{l}\text { Bird } \\
\left(\mathrm{mm}^{3}\right)\end{array}$ & $718.51 \pm 20.67$ & $742.25 \pm 28.36$ & $689.03 \pm 17.0 \#$ & $759.91 \pm 24.62 \#$ & $730.38 \pm 17.35$ & 0.055 & 0.095 \\
\hline
\end{tabular}


Table 3. The mean volumes of the right and left hemispheres and the mean total male and female brain volumes in lambs, rats and birds. \#: statistically significant difference.

\begin{tabular}{lcccccc} 
& \multicolumn{2}{c}{ Lamb } & \multicolumn{2}{c}{ Rat } & \multicolumn{2}{c}{ Bird } \\
\cline { 2 - 7 } & Male & Female & Male & Female & Male & Female \\
\hline Right & $40.44 \pm 2.06$ & $37.26 \pm 1.08$ & $601.95 \pm 31.37$ & $584.36 \pm 18.68$ & $731.2 \pm 31.39$ & $700.74 \pm 24.93$ \\
Left & $39.62 \pm 1.92$ & $35.01 \pm 1.1$ & $609.52 \pm 18.25$ & $600.44 \pm 19.81$ & $788.62 \pm 37.1 \#$ & $677.33 \pm 24.82 \#$ \\
\hline
\end{tabular}

\section{DISCUSSION}

The results of our study of the volumes of brain hemispheres showed that there is no asymmetry between the right and the left hemispheres of three animal species. However, the male brain volumes in the lamb and bird were larger than those of the females. The brains of different animals have been examined for anatomical asymmetry to trace the evolution of human morphological characters and to understand better the development of language or other cognitive functions (Heilbroner and Holloway, 1989). It is known that there are functional and structural differences between brain hemispheres (Kolb et al., 1982; Mayhew et al., 1996a; 1996b). However, it is not clear if these functional differences result from morphometric differences between the brain hemispheres.

There are many different non-stereological investigations of brain asymmetry. Results of such studies have many discrepancies. Many of them report that there is a left-right interhemispheric asymmetry (Geschwind and Levitsky, 1968; Kolb et al., 1982; Tan and Çalışkan, 1987; Steinmetz et al., 1990), whereas some of them report that there is no asymmetry between brain hemispheres (Heilbroner and Holloway, 1989; Paus et al., 1996). All nonstereological studies are based on such features of the brain as height, width and length of a hemisphere, or shape of the gyri. However, as mentioned by Gundersen (1992), any particular regional volume defined in this way may vary considerably (15-25\% between individuals). Therefore, conclusive and valid findings are unlikely to be obtained using such features.

The studies of Mayhew et al. (1996a; 1996b) of surface area and volume in experimental animals indicated that mammalian brains are symmetric and not sexually dimorphic on the basis of gross anatomy. Henery and Mayhew (1989) also reported that there are no significant differences between brain hemispheres and no interaction effects but sex differences were found in fixed human brains. Our findings are similar to those of Mayhew et al. (1996a; 1996b) and Henery and Mayhew (1989) in that we found differences between male and female brains of the lamb and bird, whereas there was no such difference in the rat.

The comparison between the left and right cerebral hemispheres failed to reveal any volumetric asymmetry in lamb, rat or avian brains in this study. However, it is well known that lateralization of function and structure is a feature of human brains as well as those of other species, including other birds and lower vertebrates. We suggest that volume may be a too crude a parameter to identify such localized asymmetries, and perhaps more detailed studies of other parameters such as neuronal density would better characterize interhemispheric asymmetry or symmetry.

\section{ACKNOWLEDGEMENT}

We would like to thank anonymous reviewers for their constructive advices and also thank to Dr. David S. Knight, Department of Cellular Biology and Anatomy, Health Science Center, Louisiana State University, US for language revising of the manuscript.

\section{REFERENCES}

Barta P, Pearlson GD, Brill LB, Richard R, McGilchrist IK, Pulver AE, Rowers RE, Casanova MF, Tien AY, Frangou S, Petty RG (1997). Planum temporale asymmetry reversal in Schizophrenia: Replication an relationship to gray matter abnormalities. Am J Psychiatry 154:661-7.

Frangou S, Sharma T, Sigmudsson T, Barta P, Pearlson G, Murray RM (1997). The maudsley family study 4 . normal planum temporale asymmetry in familial Schizophrenia Br J Psychiatry 170:328-33.

Geroldi C, Laakso MP, DeCarli C, Beltramello A, Bianchetti A, Soininen H, Trabucchi M, Frisoni GB (2000). Apolipoprotein E genotype and hippocampal asymmetry in Alzheimer's disease: a volumetric MRI study. J Neurol Neurosurg Psychiatry 68:93-6. 
Gescwind N, Levitsky W (1968). Human brain: left-right asymmetries in temporal speech regions. Science 161:186-7.

Gundersen HJG, Bendtsen TF, Korbo L, Marcussen N, Móller A, Nielsen K, Nyengaard JR, Pakkenberg B, Sórensen FB, Vesterby A, West MJ (1988). Some new, simple and efficient stereological methods and their use in pathological research and diagnosis. APMIS 96:379-94.

Gundersen HJG, Jensen EB (1987). The efficiency of systematic sampling in stereology and its prediction. J Microsc 147:229-63.

Gundersen HJG (1992). Stereology: the fast lane between neuroanatomy and brain function-or still only a tightrope? Acta Neurol Scand 137(Suppl):8-13.

Heilbroner PL, Holloway RL (1989). Anatomical brain asymmetry in monkeys: frontal, temporoparietal, and limbic cortex in Macaca. Am J Phys Anthrophol 80:203-11.

Henery CC, Mayhew TM (1989). The cerebrum and cerebellum of the fixed human brain: efficient and unbiased estimation of volumes and cortical surface areas. J Anat 167:167-80.

Kolb B, Sutherland RJ, Nonneman AJ, Whishaw IQ (1982). Asymmetry in the cerebral hemispheres of the rat, mouse, rabbit and cat: the right hemisphere is larger. Exp Neurol 78:348-59.

Mayhew TM, Mwamengele GLM, Dantzer V, Williams S (1996a). The gyrification of mammalian cerebral cortex: quantitative evidence of anisomorphic surface expantion during phylogenetic and ontogenetic development. J Anat 188:53-8.

Mayhew TM, Mwamengele GLM, Dantzer V (1996b). Stereological and allometric studies on mammalian cerebral cortex with implication for medical brain imaging. J Anat 189:177-84.

Paus T, Tomaiuolo F, Otaky N, MacDonal D, Petrides M, Atlas J (1996). Human cingulate and paracingulate sulci: pattern, variability, asymmetry, and probabilistic map. Cereb Cortex 6:207-14.

Preis S, Jancke L, Schmitz-Hillebrecht J, Steinmetz H (1999). Child age and planum temporale asymmetry. Brain Cogn 40:441-52.

Schultz RT, Cho NK, Staib LH, Kier LE, Fletcher JM, Shaywitz SE, Shankweiler, DP, Katz L, Gore JC, Duncan JS, Shaywitz BA (1994). Brain morphology in normal and dyslexic children: The influence of sex and age. Ann Neurol 35:732-42.

Steinmetz H, Rademacher J, Jancke L, Huang Y, Thron A, Zilles K (1990). Total surface of temporoparietal intrasylvian cortex: diverging left-right asymmetries. Brain Lang 399:357-72.

Tan Ü, Çalıșkan S (1987). Asymmetries in the cerebral dimensions and fissures of the dog. Inter $\mathbf{J}$ Neurosci 32:943-52.

West MJ (1993). New stereological methods for counting neurons. Neurobiol Aging 14:275-85.

Williams PL, Warwick R (1989). Gray's Anatomy, $37^{\text {th }}$ ed. New York: Churchill Livingstone. 